\title{
DESAFIOS DA DIVULGAÇÃO CIENTÍFICA EM COBERTURA JORNALÍSTICA DE DESASTRE AMBIENTAL
}

\section{Challenges faced by the dissemination of science in press media coverage of an environmental disaster}

\author{
Luiz Fernando Dal Pian ${ }^{1}$. Daniel Durante Pereira Alves ${ }^{2}$
}

Resumo: A atual crise ambiental planetária sinaliza a tendência de que a humanidade deverá conviver, cada vez mais, com as catástrofes ecológicas. Assim como as diversas esferas da sociedade precisam estar preparadas para lidar com essas situações, a mídia deve estar pronta para contribuir na ampliação do debate público e na busca por soluções. Nessas circunstâncias, o grande desafio dos meios de comunicação de massa tem sido abordar os conceitos ligados à ciência ambiental, por se tratar de uma área de conhecimento nova e complexa. Para contribuir com o tema, a pesquisa estudou a cobertura jornalística, realizada pela mídia impressa, de um evento que envolveu a mortandade de peixes num estuário de Natal-RN. A análise de conteúdo jornalístico identificou o tratamento um tanto precário dos conceitos científicos capazes de fundamentar os reais motivos relacionados à mortandade de toneladas de fauna aquática, contribuindo pouco para a formação e educação ambiental dos leitores.

Palavras-chave: Divulgação científica. Jornalismo ambiental. Sustentabilidade. Mortandade de peixes. Rio Potengi.

\begin{abstract}
The current global environmental crisis indicates that humanity will live, increasingly, with ecological catastrophes. Different spheres of society must be prepared to cope with these situations. Particularly, media must be ready to contribute to the expansion of public debate and to search for solutions. In these circumstances, the main challenge of mass media is to broach concepts related to environmental sciences, because it is a new and complex knowledge area. To contribute to the subject, this research studied press media coverage of a large fish kill along an estuary of Natal, in Brazil. Thematic content analysis of newspaper reports identified a somewhat precarious treatment of scientific concepts that could substantiate the actual causes of mortality of tons of aquatic fauna, signaling a poor contribution to environmental education and to the scientific understanding of readers.
\end{abstract}

Keywords: Scientific dissemination. Environmental journalism. Sustainability. Fish kill. Potengi river.

\footnotetext{
${ }^{1}$ Universidade de São Paulo (USP), Escola de Comunicações e Artes (ECA), Avenida Prof. Lúcio Martins Rodrigues, 443, Cidade Universitária, CEP 05508-020, São Paulo, SP, Brasil. E-mail: lfdalpian@usp.br ${ }^{2}$ Universidade Federal do Rio Grande do Norte (UFRN), Departamento de Filosofia, Natal, RN, Brasil.
} 


\section{Introdução}

O desenvolvimento científico e tecnológico dos séculos XIX e XX proporcionou diversas melhorias e conquistas à humanidade, ao mesmo tempo que gerou impactos negativos, sobretudo ao meio ambiente (CÂMARA, 2003). Vivemos, hoje, uma era de enorme expansão do conhecimento científico e de suas aplicações, de modo que é indispensável o fortalecimento do debate público, nos mais diversos níveis, acerca do papel ocupado pela Ciência, Tecnologia e Inovação para a sustentabilidade do planeta. Uma forma de promover a divulgação das informações referentes às ciências ambientais é por meio dos veículos de comunicação de massa, fazendo uso, sobretudo, do jornalismo científico.

"Na grande mídia, a questão ambiental costuma ter mais destaque no noticiário quando se trata de desastre" (PESSOA, 2008, p. 1). As catástrofes ambientais costumam expor não apenas a degradação do meio ambiente, mas, também, a limitação dos meios de comunicação de massa em abordar o tema, pois, nesses casos, predomina uma cobertura jornalística denunciativa, sensacionalista, com pouco aprofundamento dos dados científicos e raras abordagens educativas (DAL PIAN, 2011). Daí a importância de os profissionais da imprensa buscarem realizar uma cobertura que possibilite explicar os fenômenos ambientais e os relacionar com o cotidiano das pessoas.

O presente artigo visa dar uma contribuição à questão por meio de um estudo de caso, em que um desastre ambiental ocorrido no Rio Grande do Norte, em 2007, chamou a atenção da sociedade e dos órgãos competentes, especialmente pelo destaque que a imprensa local deu ao fato. Nos dias 28 e 29 de julho daquele ano, toneladas de peixes, crustáceos e outros organismos foram encontrados mortos em áreas de mangue, às margens do Rio Jundiaí, afluente do Potengi, nos limites de Natal, São Gonçalo do Amarante e Macaíba.

Visando levar à população informações que pudessem esclarecer a causa do desastre, os jornalistas escutaram diversas fontes envolvidas com o caso e suas diferentes versões sobre a questão. Dal Pian (2011) identificou a predominância de sete termos técnico-científicos, na cobertura da mídia impressa natalense, entre fenômenos, métodos e substâncias, utilizados para tentar explicar o que motivou a mortandade dos peixes. Foram eles: Maré Vermelha, Metais Pesados, Amônia, Metabissulfito de Sódio, Demanda Bioquímica de Oxigênio (DBO), Demanda Química de Oxigênio (DQO) e Eutrofização.

O estudo buscou verificar como esses conceitos foram usados pelos jornalistas para explicar as causas da mortandade e para caracterizar os desdobramentos quanto à apuração das responsabilidades.

\section{Fundamentação teórica}

A relação entre ciência, tecnologia, sociedade e meio ambiente ficou cada vez mais próxima, de modo que se torna impossível conceber o desenvolvimento de uma sem gerar alguma consequência em outra. O esclarecimento público em torno dessas questões que envolvem os riscos e benefícios potenciais deve ser estimulado, e o jornalismo surge como importante ferramenta para a disseminação de informações que possam contribuir para o processo democrático. "A divulgação da ciência é hoje instrumento necessário para consolidar 
a democracia e evitar que o conhecimento seja sinônimo de manipulação e poder" (CANDOTTI, 2001, p. 5).

No entanto, a divulgação científica nos veículos de comunicação de massa, no Brasil, ainda ocupa um espaço pouco expressivo, ficando restrita às notícias de grande apelo como: descoberta de novos planetas, curas de doenças, clonagem de animais ou derretimento das calotas polares. De acordo com Bueno (2010), embora possamos registrar um crescimento da divulgação científica no Brasil, o cenário atual ainda está longe do ideal. Na grande mídia, a ciência e a tecnologia ficam relegadas a segundo plano, restritas a notas e notícias isoladas, numa cobertura que busca sempre valorizar o espetáculo e o sensacionalismo.

Não há como desconsiderar os benefícios que os avanços científicos e tecnológicos trouxeram para humanidade, ao longo da história, especialmente nos dois últimos séculos. Controle e eliminação de doenças, crescimento na produção de alimentos, aumento da expectativa de vida, transporte de massa, conforto, entretenimento e comunicação em rede, foram algumas dessas importantes conquistas. Mas, durante boa parte dessa trajetória, pouco foi discutido a respeito dos impactos que tais benefícios poderiam ocasionar ao meio ambiente. Até a década de 1960, organizações mundiais tratavam as mudanças climáticas como questões secundárias, em face de outras, predominantemente questões econômicas e militares (MARCOVITCH, 2007). Como marcos importantes no processo de tomada de consciência, podemos citar o lançamento do livro Primavera Silenciosa ${ }^{3}$, em 1962, e o relatório Limites do Crescimento, elaborado pelo Clube de Roma, em 1968, quando especialistas questionaram o modelo de desenvolvimento adotado até então. Apesar de o relatório ter encontrado dificuldades para predizer o futuro, alertou o mundo sobre os riscos do crescimento econômico desenfreado (MOTA, 2001).

O desenvolvimento da ciência e da tecnologia deu, ao ser humano, maiores poderes para intervir e modificar o mundo natural, o que acarreta em impactos ambientais graves, por meio do aumento na emissão de gases de efeito estufa, poluição dos mananciais, desflorestamento, perda de biodiversidade, uso de pesticidas na agricultura, entre outros. Desta forma, os jornalistas precisam incorporar mais os princípios de sustentabilidade e abandonar a ideia de que ciência e tecnologia são eticamente neutras, ou seja, "de que os problemas que causam residem no uso que se faz delas e não na sua existência. Na verdade, não há conhecimento humano sem intencionalidade, muito menos conhecimento científico e tecnológico" (ROMANINI, 2005, p. 110).

\footnotetext{
${ }^{3}$ Livro escrito pela bióloga e zoóloga norte-americana Rachel Carson, publicado em setembro de 1962, creditado como um marco inicial dos movimentos ambientalistas. A obra, que chegou a figurar entre os mais vendidos de não ficção, denunciou os malefícios, para o ambiente natural, do uso de determinados tipos de pesticidas na agricultura dos Estados Unidos.
} 


\section{Jornalismo, ciência e sustentabilidade}

Para contextualizar essa discussão, é importante apontar as diferenças entre os termos divulgação científica e comunicação científica. O primeiro se refere ao uso de processos e recursos técnicos para a comunicação da informação científica e tecnológica ao público em geral, ao não-especialista, ao leigo. Já o segundo diz respeito à comunicação de informação científica e tecnológica, transcrita em códigos especializados, para um público seleto de pessoas com formação científica e tecnológica.

De acordo com Albagli (1996), a divulgação científica faz uso de importantes instrumentos, como: livros, museus e centros de ciência, além da mídia. Como um dos instrumentos da mídia para divulgação, ela destaca o jornalismo científico, que pode ser definido como um processo social baseado em uma frequente e oportuna relação entre organizações formais (estabelecimentos/redes de editores) e comunidades (público/espectadores), que tem lugar através dos veículos de comunicação, como jornais, revistas, rádio, TV e internet, e que circula informação atualizada sobre a natureza científica e tecnológica, de acordo com variados graus de interesse e expectativa (universos culturais e ideológicos).

No entanto, são muitos os conflitos e desafios encontrados no processo de elaboração do material jornalístico sobre ciência e tecnologia. No que diz respeito à questão ambiental, o profissional da imprensa precisa desempenhar uma das principais funções jornalísticas contemporâneas nas sociedades democráticas: a de promover a informação de forma contextualizada, aprofundando os fatos e explicando os conceitos. Um dos grandes desafios enfrentados pelos jornalistas científicos tem sido abordar os termos técnicos das ciências ambientais, por se tratar de uma área nova, complexa e multidisciplinar.

Mesmo que a imprensa não tenha como promover a educação ambiental formal, tal como é feita nas escolas, segundo Girardi e Schwaab (2008), o entendimento do papel do jornalismo como forma de conhecimento permite um elo com os pressupostos da educação ambiental, que tem como principal objetivo o pleno exercício da cidadania e o acesso à informação de modo a subsidiar um modo de pensar sistêmico. A ideia é corroborada por Dornelles (2008), quando afirma que a pauta ambiental precisa, fundamentalmente, desempenhar uma função pedagógica, sistematizando conceitos, disseminando informações, conhecimentos e vivências, ou seja, dando condições para que o cidadão comum participe do debate e tenha uma visão crítica da realidade.

Além do desafio de traduzir uma linguagem técnica - dominada por um grupo específico de pesquisadores e intelectuais - para uma linguagem acessível a um público de massa, os jornalistas que cobrem diariamente os temas ambientais dispõem de poucas horas ou até minutos, num processo de produção de notícias repleto de interferências logísticas, estruturais, econômicas e políticas. Segundo Barbosa (2003), o acontecimento descrito pelos jornalistas, em forma de notícias, não representa a realidade em si, mas, sim, uma reconstrução da realidade, do ponto de vista do narrador, que é submetido aos limites ideológicos do seu tempo e às estruturas às quais está filiado.

Barbosa (2003) cita a pesquisa do semiólogo argentino Eliséo Veron, intitulada Construir o acontecimento, destacando que as mídias não descrevem, mas constroem a realidade. Assim, o mundo configurado pelas notícias é sempre uma realidade construída. 
Considera-se, pois, o acontecimento não como ocorrência espacial e temporal, mas como algo que, ao ser editado, selecionado, escolhido, recebe sentidos atribuídos pelos chamados operadores da mídia. Nessa perspectiva, portanto, os acontecimentos públicos seriam produto ou resultado das atividades, das práticas rotineiras e das estratégias de um certo número de atores sociais. (BARBOSA, 2003, p. 221)

No caso em estudo, “a construção do acontecimento" pelos profissionais da imprensa, dentro de uma perspectiva de causalidade, ganha em complexidade a partir da utilização de um conjunto de termos científicos (citados na Introdução) que tem conceituação estabelecida pela literatura especializada ligada à Limnologia e à Oceanografia e que, como veremos nos resultados, são de difícil tratamento jornalístico. O referencial teórico desses conceitos é resumido a seguir.

\section{Desastre ambiental no estuário do rio Potengi: sete conceitos relevantes}

\section{Maré Vermelha}

O fenômeno Maré Vermelha corresponde ao crescimento excessivo de algas microscópicas presentes no plâncton marinho, num processo chamado de floração. A terminologia está relacionada às manchas de coloração avermelhada no mar, porém, dependendo da espécie de alga, a mancha pode adquirir coloração marrom, laranja, roxa ou amarela. Uma vez que a água nem sempre fica vermelha, o termo "maré vermelha" vem sendo substituído por "Floração de Algas Nocivas" ou simplesmente FAN.

Na maioria dos casos, o fenômeno é causado pela floração de pequenos organismos unicelulares, eucariontes, pertencentes ao Reino Protista, chamados de dinoflagelados. Os ciclos vitais dos dinoflagelados são controlados, sobretudo, pelos seguintes fatores: a temperatura, salinidade, luminosidade, quantidade de oxigênio e disponibilidade de nutrientes na água. Desta forma, tendem a se desenvolver mais nas faixas continentais de baixas e médias latitudes, onde esses fatores são mais favoráveis (ARAI, 2007). O enriquecimento de nutrientes nos corpos d'água pode ser acentuado por ações antrópicas, como lançamento de efluentes sem tratamento.

De acordo com Arai (2007), as Marés Vermelhas se constituem de florações explosivas - com frequência até 20 milhões e, excepcionalmente, mais de um bilhão de células por litro. A decomposição subsequente de suas células provoca uma drástica diminuição no teor de oxigênio na água, levando à morte de diversos organismos que dependem de oxigênio dissolvido. Alguns dinoflagelados produzem toxinas e podem causar eventos de mortandade ainda mais graves, levando a consequências catastróficas.

\section{Metais pesados}

De acordo com Santana (2008), os metais pesados são elementos químicos que foram classificados, inicialmente, em função da densidade. Por vários anos, esse critério de definição 
foi modificado, gerando divergências quanto aos valores de densidade, que chegaram a variar entre maior do que 4 e maior do que $6 \mathrm{~g} / \mathrm{cm}^{3}$. A classificação desses elementos em relação à densidade perdeu força e a utilização do termo "acabou sendo estigmatizada, no decorrer das décadas, por muitos autores em vários trabalhos científicos, que atribuíram a estes elementos riscos de toxicidade e ecotoxicidade nos diversos compartimentos do ambiente" (CHAVES, 2008, p. 5).

De acordo com Tavares e Carvalho (1992, p. 147), erroneamente, todos os metais considerados tóxicos aos seres humanos passaram a ser classificados como metais pesados. "Na realidade, metal pesado é aquele que apresenta alto peso específico". De acordo com Art (1998), metais pesados são aqueles metais com número atômico de médio a alto, como o cobre, o cádmio, a prata, o arsênio, o cromo e o mercúrio, e que são tóxicos em concentrações relativamente baixas. Persistem no ambiente e podem se acumular em níveis que interrompem o crescimento das plantas e interferem na vida animal. Os detritos de atividades mineradoras e industriais e o lodo de esgoto são fontes de concentrações de metais pesados potencialmente prejudiciais.

\section{Amônia}

Nitrogênio amoniacal, ou simplesmente amônia, pode estar presente em água natural, em baixos teores, tanto na forma ionizada $\left(\mathrm{NH}_{4}^{+}\right)$como na forma tóxica não ionizada $\left(\mathrm{NH}_{3}\right)$, devido ao processo de degeneração biológica de matéria orgânica animal e vegetal. Segundo Guedes (2003), trata-se de uma substância tóxica, correspondente ao produto inicial da decomposição de efluentes orgânicos nitrogenados (ureia, proteínas, aminoácidos). Sua presença nas águas naturais costuma estar relacionada aos resíduos de fertilizantes. $\mathrm{O}$ nitrogênio, em seu ciclo na biosfera, se alterna em várias formas e estados de oxidação. No meio aquático, o nitrogênio pode ser encontrado nas seguintes formas: "(a) nitrogênio molecular $\left(\mathrm{N}_{2}\right)$, escapando para a atmosfera, (b) nitrogênio orgânico (dissolvido e em suspensão), (c) amônia (livre $\mathrm{NH}_{3}$ e ionizada $\mathrm{NH}_{4}^{+}$), (d) nitrito $\left(\mathrm{NO}_{2}^{-}\right.$) e (e) nitrato $\left(\mathrm{NO}_{3}^{-}\right.$)" (SPERLING, 2005, p. 36).

Embora a amônia seja somente um pequeno componente no ciclo total do nitrogênio, contribui para a fertilização da água, tendo em vista que o nitrogênio é um essencial nutriente para as plantas. A amônia é uma substância tóxica não persistente e não cumulativa e sua concentração tipicamente baixa $(0,1 \mathrm{mg} / \mathrm{L})$ não afeta o homem, nem os mamíferos em geral. Em valores acima dos permitidos pelo CONAMA $(0,4 \mathrm{mg} / \mathrm{L}$ para águas salobras) pode contribuir para a morte de peixes por asfixia, pois reduz a capacidade de transporte de oxigênio do sangue destes animais (UNIVERSIDADE TECNOLÓGICA FEDERAL DO PARANÁ, 2002).

\section{Metabissulfito de sódio}

O metabissulfito de sódio $\left(\mathrm{Na}_{2} \mathrm{~S}_{2} \mathrm{O}_{5}\right)$ é um agente antioxidante, em forma de pó cristalino de coloração branca, podendo ser levemente amarelada. Na carcinicultura, é usado para prevenir a formação da melanose (mancha preta) ou black spot, que reduz a qualidade do produto no mercado) em camarões durante a fase de processamento, logo após a despesca/ coleta. "Após a coleta e resfriamento, os camarões devem ser imediatamente imersos em uma 
solução de água com metabissulfito em uma concentração de 5 a $8 \%$ a uma temperatura próxima de $0^{\circ} \mathrm{C}$, durante um período de 10 a 15 minutos" (ALBUQUERQUE, 2005, p. 30).

A solução de metabissulfito de sódio não consumida durante o processo de despesca é o rejeito que quase sempre é descartado no ambiente sem nenhum tratamento. Este rejeito líquido pode causar impactos negativos nos corpos d'água naturais, pois reduz o oxigênio dissolvido, diminui a alcalinidade total e ocasiona a queda do $\mathrm{pH}$ da água, podendo resultar na morte de vários seres vivos do ambiente aquático em que houve o descarte. A legislação ambiental vigente do Conselho Nacional de Meio Ambiente (CONAMA) n 20 - art. 21 de 18/06/1986, determina que o teor de sulfito contido em efluentes lançados nos corpos d'água só poderá ser de até 1,0 ppm. "No entanto, a solução de sulfito utilizada durante a despesca contém em média, 50.000 ppm" (ALBUQUERQUE, 2005, p. 2).

\section{Demanda bioquímica de oxigênio}

Segundo Guedes (2003), a Demanda Bioquímica de Oxigênio (DBO) é um indicador de concentração de matéria orgânica, obtido pela medida da quantidade de oxigênio dissolvido necessária para consumo de organismos aeróbios, na oxidação de matéria orgânica biodegradável e de outras substâncias capazes de consumir $\mathrm{O}_{2}$. O lançamento de esgotos ricos em matéria orgânica nos cursos d'água, por exemplo, estimula o aparecimento de microorganismos que vão consumir oxigênio da água através da oxidação bioquímica. Desta maneira, a DBO funciona como um indicador que determina indiretamente a concentração de matéria orgânica biodegradável através da demanda de oxigênio exercida por microrganismos através da respiração.

A DBO é um teste padrão, realizado a uma temperatura constante de $20^{\circ} \mathrm{C}$ e durante um período de incubação também fixo de cinco dias. É uma medida que procura retratar, em laboratório, o fenômeno que acontece no corpo d'água. Geralmente, uma amostra é coletada em duplicata e, em uma das amostras, é medido o oxigênio dissolvido após a coleta; o oxigênio da outra amostra é medido após cinco dias, período em que a amostra fica em uma incubadora a uma temperatura de $20^{\circ} \mathrm{C}$. A diferença de concentração de oxigênio representa a demanda bioquímica de oxigênio (VALENTE; PADILHA; SILVA, 1997).

\section{Demanda Química de Oxigênio}

A Demanda Química de Oxigênio (DQO) é um indicador de matéria orgânica baseado na concentração de oxigênio consumido para oxidar a matéria orgânica, biodegradável ou não, em meio ácido e condições energéticas por ação de um agente químico oxidante forte (VALENTE; PADILHA; SILVA, 1997). De acordo com Jardim e Canela (2004), sob uma ótica de tratamento de efluentes, a oxidação química é uma forma de transformar moléculas ambientalmente indesejáveis em outras moléculas menos tóxicas, para que estas possam ser assimiladas de modo mais harmonioso nos ciclos da natureza.

A DQO apenas estima a concentração de matéria orgânica em termos de oxigênio consumido, já que nos corpos d'águas as condições não são tão energéticas, além do fato de que algumas formas inorgânicas, tais como nitritos, compostos reduzidos de enxofre e substâncias orgânicas - como hidrocarbonetos aromáticos, compostos alifáticos de cadeia aberta e 
piridinas - não são oxidadas. A principal vantagem da DQO é a rapidez, pouco mais de duas horas, enquanto a DBO leva cinco dias (VALENTE; PADILHA; SILVA, 1997).

\section{Eutrofização}

A eutrofização pode ser caracterizada pelo aumento de nutrientes em um corpo d'água, sobretudo o nitrogênio e o fósforo. De acordo com Sperling (2005), este fenômeno implica o crescimento excessivo das plantas aquáticas, tanto planctônicas quanto aderidas, a níveis tais que sejam considerados como causadores de interferências com os usos desejáveis do corpo d'água.

O processo de eutrofização pode ser natural, devido a erosões, chuvas e ventos no decorrer de centenas de anos. Mas, na maioria dos casos, se dá pela ação humana, com o despejo de esgotos domésticos, industriais e agrícolas, ricos em matéria orgânica, sendo estes classificados como eutrofização cultural. A aglomeração de algas na superfície do corpo d'água impede a penetração da energia luminosa, prejudicando a fotossíntese realizada por algas situadas nas camadas inferiores, o que diminui os níveis de oxigênio dissolvido.

O crescimento dessas plantas aquáticas tende a aumentar gradativamente, produzindo mais matéria orgânica, que será decomposta por bactérias aeróbias, diminuindo ainda mais a quantidade de oxigênio dissolvido. Essa reação em cadeia resulta num corpo d'água com alta turbidez, maus odores, baixas taxas de oxigênio e poucas condições para a manutenção da biodiversidade aquática. O fenômeno é mais comum em lagos e represas, mas também há registros em rios e regiões estuarinas.

\section{Materiais e métodos}

O presente estudo utilizou, como procedimento metodológico, a análise de conteúdos técnico-científicos ambientais utilizados pelos jornalistas, por meio do estudo dos "acontecimentos construídos" pela mídia impressa de Natal/RN, dentro de uma perspectiva de busca pela identificação da causa do desastre ambiental.

Para tal, tivemos acesso a toda "clipagem" (recorte e arquivamento de registros jornalísticos) realizada pelo Instituto de Desenvolvimento Sustentável e Meio Ambiente do Rio Grande do Norte (IDEMA), um dos grandes citados e interessados no caso em estudo, que, por meio de sua assessoria de comunicação, realizou um rígido controle do que foi publicado pela imprensa local à época do ocorrido. Os jornais escolhidos para análise foram os matutinos Tribuna do Norte e Diário de Natal; além dos vespertinos Jornal de Hoje e Correio da Tarde, por serem aqueles com maior circulação e penetração, à época da pesquisa, na região metropolitana de Natal, área que envolve nosso estudo.

\section{Localização geográfica e estudo de caso}

O Estuário do rio Potengi está localizado no litoral oriental do estado do Rio Grande do Norte, adentrando, por aproximadamente vinte $\mathrm{km}$, na bacia hidrográfica do rio Potengi. Sua nascente está localizada na Serra de Santana, no município de Cerro Corá, e o rio percorre 
$176 \mathrm{~km}$ até sua foz. Antes de desaguar no Oceano Atlântico, recebe alguns afluentes importantes, como o rio Jundiaí, rio Golandim e o Rio Doce, formando o Estuário do Potengi (também chamado de Estuário Potengi-Jundiaî). Atualmente, as atividades mais impactantes são aquelas resultantes: do distrito industrial de São Gonçalo do Amarante e Extremoz, dos viveiros de camarão, dos efluentes das imunizadoras e dos esgotos domésticos lançados sem tratamento nas águas do rio.

Às margens do rio Jundiaí, próximo ao encontro com o Potengi, toneladas de peixes, crustáceos e outros organismos foram encontrados mortos em áreas de mangue, nos dias $28 \mathrm{e}$ 29 de julho de 2007, nos limites entre Natal, São Gonçalo do Amarante e Macaíba. A empresa de carcinicultura Veríssimo e Filhos Ltda. recebeu punição administrativa do IDEMA, por meio de uma multa no valor de $\mathrm{R} \$ 500$ mil, além de ter sua licença de operação suspensa, mas recorreu da decisão junto ao Conselho Estadual de Meio Ambiente (CONEMA). De acordo com um laudo preliminar emitido pelo IDEMA, em agosto de 2007, e corroborado por um parecer técnico elaborado por uma comissão de especialistas da Universidade Federal do Rio Grande do Norte (UFRN), em janeiro de 2009, o desastre foi ocasionado pelo "lançamento de efluentes líquidos, nos dias 27 e 28/07/2007, com elevada carga de matéria orgânica, sem tratamento, originário da despesca de um viveiro de camarão diretamente no rio Jundiaí, afluente do rio Potengi" (DAL PIAN, 2011, p. 100).

Em fevereiro de 2010, ocorreu uma reunião do CONEMA para discutir o processo, mas os representantes do Conselho não chegaram a um consenso, o que inviabilizou uma decisão definitiva e o processo acabou protocolado. Outras reuniões estavam marcadas para março e abril do mesmo ano, visando decidir pela punição ou absolvição da empresa, mas foram adiadas, sem uma explicação plausível por parte da presidência do Conselho. O Ministério Público (MP) também participa da investigação para apurar as responsabilidades cíveis e criminais. Todas as ações ainda transcorrem na Justiça Estadual e, até o momento, não houve um desfecho oficial para o caso.

\section{Etapas do estudo}

A fase inicial da pesquisa que resultou neste artigo separou, para análise, duzentos e vinte registros jornalísticos publicados no período de 30 de julho de 2007 a 28 de julho de 2010. Após uma primeira leitura desse total, pudemos identificar 34 notícias que tinham como característica comum a tentativa de explicar os motivos do desastre, utilizando os sete termos científicos citados, entre fenômenos, substâncias e métodos. Segundo Pessoa (2008), a cobertura jornalística relativa às catástrofes ambientais deve conduzir o leitor à reflexão, estimulando a visão crítica, explicando as causas e as consequências do que é informado. Desta forma, realizamos uma análise qualitativa desses sete termos técnico-científicos dentro das seguintes abordagens:

. Definição: Como o jornalista construiu o conceito em torno do termo. Relacionouo com o que, com que tipo de ideia.

. Causa: Para as substâncias, métodos e/ou parâmetros, qual a fonte emissora. Para os fenômenos, quais as condições e fatores desencadeantes.

. Consequência: Quais os impactos para o ambiente, fauna, flora e sociedade daquelas ações. 
- Apuração das responsabilidades: Como o termo foi relacionado com as investigações, com as hipóteses levantadas, com as suspeitas, acusações e defesas.

Em alguns casos, os termos recebiam, nas matérias, mais de uma dessas abordagens, que foram todas analisadas e computadas. Os casos em que não identificamos qualquer tipo de abordagem também foram somados. Esses dados foram tabulados no programa Excel e a maior parte deles foi apresentada textualmente no item Resultados e Discussões. Visando subsidiar a fase final de análise, inferências e interpretações, comparamos os conteúdos construídos pelos jornalistas com informações retiradas de bibliografia especializada na área, encontradas em livros, artigos científicos disponíveis nos periódicos da CAPES, teses e dissertações no banco de dados da UFRN e publicações governamentais.

\section{Resultados e discussões}

Os sete termos científicos explorados pelos jornalistas na tentativa de explicar as causas que levaram à mortandade da fauna aquática tiveram um total de 38 aparições (dentro da amostragem de 34 notícias), sendo a "Maré Vermelha" a mais citada, com nove registros; seguida de "Metais Pesados" e de "Amônia", sete registros cada; "Metabissulfito de Sódio" e "Demanda Bioquímica de Oxigênio", com seis registros cada; "Eutrofização", com dois; e, por último, "Demanda Química de Oxigênio", com apenas um registro. Essas notícias foram publicadas no período de cinco semanas, entre a última semana de julho e a última semana de agosto de 2007 - como apresentado na Tabela 1 - com exceção do termo "Demanda Química de Oxigênio", que foi abordado em uma notícia de março de 2010, numa tentativa de reviravolta do caso. Abaixo, discutiremos como esses conceitos foram expostos durante a cobertura jornalística.

Tabela 1. Ocorrências dos termos técnico-científicos durante cinco semanas - 30/07 a 31/08/2007.

\begin{tabular}{lcccccc}
\hline & $\mathbf{1}^{\text {a }}$ semana & $\mathbf{2}^{\text {a }}$ semana & $\mathbf{3}^{\text {a }}$ semana & $\mathbf{4}^{\text {a }}$ semana & $\mathbf{5}^{\text {a }}$ semana & Total \\
\hline Maré Vermelha & 4 & 4 & 1 & 0 & 0 & 9 \\
Metais Pesados & 4 & 1 & 0 & 1 & 1 & 7 \\
Amônia & 2 & 0 & 1 & 0 & 4 & 7 \\
Metabissulfito de Sódio & 4 & 0 & 2 & 0 & 0 & 6 \\
DBO & 0 & 4 & 0 & 1 & 1 & 6 \\
Eutrofização & 1 & 0 & 1 & 0 & 0 & 2 \\
DQO & 0 & 0 & 0 & 0 & 0 & 0 \\
\hline
\end{tabular}

Fonte: Dal Pian (2011).

\section{Maré Vermelha}

Houve a predominância por associar o termo a um fenômeno natural de proliferação de algas tóxicas de causa natural, sobretudo pelas fontes oficiais do IDEMA, que participavam da investigação do caso. Isso ocorreu nos dez primeiros dias da cobertura. Neste período, 
em duas notícias, foi desconsiderada a causa natural, quando um pescador, um professor universitário e um ambientalista acreditaram em causa antropogênica. A emissão do laudo preliminar do IDEMA, no dia 10/08/2007, corroborou a suspeita antropogênica, ao apontar a despesca de um viveiro de camarão como o agente causador. Uma notícia do jornal Tribuna do Norte (IDEMA..., 2007, p. 10) destacou que "A carga de matéria orgânica diminuiu bruscamente a taxa de oxigênio, criando uma maré vermelha artificial e matando os peixes e crustáceos", utilizando como fonte para tal afirmação o laudo emitido pelo IDEMA. No entanto, o laudo, em momento algum, cogita uma "maré vermelha artificial", até porque cita apenas a atividade de bactérias aeróbias na decomposição da matéria orgânica, e não de algas nocivas.

A abordagem da "Maré Vermelha" como um fenômeno natural de proliferação de algas que liberam toxinas nocivas aos peixes é aceita por especialistas da área. No entanto, não foi citado, pelos jornais, o tipo de alga que comumente está relacionado ao fenômeno, nem como ocorre o processo de proliferação das toxinas e/ou desoxigenação da água que leva à morte dos animais. Na maior parte dos casos, não foram citadas, sequer, quais as consequências do fenômeno no ambiente. Além disso, não foram esclarecidos os fatores estimulantes para a proliferação dessas algas na região do estuário do Potengi.

\section{Metais pesados}

Predominou o termo como algo tóxico, nocivo e causador de doenças aos seres vivos. Em alguns casos, o jornalista lembrou que alguns metais, em pequenas quantidades, são necessários ao funcionamento das funções vitais dos seres vivos, conceito corroborado por especialistas. Em uma oportunidade, o jornalista situou a posição desses metais entre "o cobre e o chumbo na tabela periódica". No entanto, alguns autores consideram outros elementos a mais como metais pesados, de acordo com o seu peso atômico e o seu nível de toxicidade.

Como causa da concentração de metais pesados, houve um direcionamento inicial para a atividade das imunizadoras, destacando, em uma oportunidade, os altos níveis destes metais no efluente da Imunizadora Potiguar. Em seguida, associou-se a emissão da substância ao lançamento de efluentes domésticos, industriais e de outras atividades econômicas realizadas ao longo do rio. A concentração de metais pesados como fator causal da morte dos peixes perdeu força nos jornais, a partir do dia 28/08/2007, após o pronunciamento do representante do Instituto de Ciências do Mar (Labomar) da Universidade Federal do Ceará (responsável pela análise de metais), Luiz Drude Lacerda, que afirmou serem necessárias concentrações bem maiores dessas substâncias, do que as constatadas nas análises, para provocar uma mortandade daquela dimensão, corroborando o laudo preliminar do IDEMA, emitido no dia 10/ 08/2007.

Os jornalistas citaram alguns metais "mais nocivos", "menos nocivos", mas não discriminaram que metais seriam esses, e nem quais seriam submetidos às análises. Outro ponto importante que não nos ficou claro diz respeito às fontes poluidoras que emitem os metais pesados, especificando apenas, nos primeiros dias de cobertura, as imunizadoras, que utilizariam essas substâncias para o tratamento de efluentes antes de serem jogados no rio. No geral, a imprensa conseguiu tornar público, dentro das limitações operacionais do jornalismo impresso diário, a existência desses metais no Estuário do Potengi-Jundiaí, de seus malefícios para a saúde humana, e a necessidade de serem estimuladas medidas mitigadoras para o problema. 
Amônia

Predominou o termo amônia como uma substância química e tóxica aos seres vivos, mas sem explicar, inicialmente, o porquê. Olimpio Marodim, representante da Cooperativa dos Carcinicultores do Vale do Jundiaí, negou a utilização da substância pela criação de camarão e acusou a descontaminação dos tanques da fábrica da RC Cola, que havia sido recentemente comprada pela empresa Norsa, fabricante e distribuidora da Coca-Cola em vários estados do Nordeste. Segundo esta fonte, a fábrica teria utilizado excessiva quantidade de "soda cáustica, água sanitária, muitos químicos que geram amônia” (IDEMA..., 2007, p. 10) e, em seguida, esses efluentes teriam sido levados à lagoa de tratamento da Imunizadora Potiguar para serem despejados no Rio Jundiaí. O carcinicultor ainda desconsidera os riscos da amônia nos peixes para consumo, posicionando-se contra a proibição da pesca imposta pelo IBAMA, na época, ao afirmar que "o excesso de amônia só tira o oxigênio da água, o que causa a mortandade, mas não contamina o peixe a ponto de não servir como alimento humano" (IDEMA..., 2007, p. 10).

Já o representante dos pescadores de Macaíba negou uma suposta utilização de materiais de limpeza com amônia pelas comunidades ribeirinhas, e denunciou que a substância vinha sendo despejada por uma indústria, mas preferiu não revelar o nome, e afirmou, ainda, que o caso vinha sendo denunciado há cerca de um ano e meio ao IDEMA, sem ter sido tomada nenhuma providência.

A principal consequência do excesso de concentração da substância em corpos aquáticos foi explicada quando o representante do Instituto de Ciências do Mar (Labomar), Luiz Drude Lacerda, no dia 28/08/2007, se pronunciou sobre os resultados de suas análises, corroborando o laudo preliminar do IDEMA. Nessas oportunidades, o biólogo afirmou que "o processo foi acelerado e facilitado pelas elevadas concentrações de amônia, cuja toxidez ocorre justamente pela diminuição da capacidade de utilização do oxigênio pelos organismos" (LABOMAR..., 2007, p. 8), fazendo menção à capacidade da amônia, quando em excesso, de reduzir a circulação de oxigênio no sangue dos peixes. Como a afirmação foi divulgada igualmente pelos jornais, presume-se que esta fonte enviou uma nota à imprensa, que a publicou na íntegra.

Em defesa dos carcinicultores, o presidente da Associação Brasileira dos Criadores de Camarão (ABCC), Itamar Rocha, acusou o IDEMA de perseguição e de desconsiderar resultados de amostras do despejo de efluentes da Imunizadora Potiguar. "As amostras comprovaram que no efluente da Imunizadora Potiguar, que foi a única coleta que não foi feita no rio (dia 29 de julho), a concentração de amônia era 164 vezes superior ao permitido pelo Conama (65 contra 0,4 mg/L) e não tomaram nenhuma providência, é um crime" (ASSOCIAÇÃO..., 2007, p. 12). Apesar da afirmação, ele não atribui a culpa pelo desastre ambiental às imunizadoras, ao destacar que a CAERN despeja mais esgotos nos rios Jundiaí e Potengi do que essas empresas.

No geral, a possibilidade da mortandade dos peixes pelo excesso de amônia foi levantada, mas não confirmada pela cobertura. Atribuiu-se o despejo da substância às imunizadoras, que estariam tratando, além do esgoto doméstico, resíduos da fábrica da Coca-cola. Destacou-se a consequência do excesso da amônia, que é agravada com a desoxigenação das águas, porém não foi explicado como ocorre o processo. Além disso, não houve qualquer menção à substância como um componente do ciclo biogeoquímico do nitrogênio. 
Desafios da divulgação científica ...

\section{Metabissulfito de sódio}

A hipótese da mortandade dos peixes pelo lançamento da substância metabissulfito de sódio foi levantada pela imprensa, a partir do dia 01/08/2007, com informações do geólogo, professor do Instituto Federal de Educação, Ciência e Tecnologia do Rio Grande do Norte (IFRN) e consultor do IDEMA, Ronaldo Diniz. Os jornais abordaram a substância como algo utilizado pela carcinicultura para prevenir a formação da melanose em camarões, durante a fase de despesca. O jornal Tribuna do Norte, do dia 01/08/2010, buscou uma definição mais completa, por meio de um "box" informativo, onde se referiu à substância como um "agente oxidante", mas sem especificar em que situação. Segundo as referências especializadas, o metabissulfito de sódio age como um agente antioxidante na carcinicultura, com funções conservativas e de esterilização.

Representantes de cooperativas de criadores de camarão foram ouvidos e trataram de minimizar o fato, ao garantirem que o metabissulfito entrou em desuso, pode ser neutralizado com cal e não é despejado nas águas do rio, e sim no solo. Inclusive, este setor acusou a Imunizadora Potiguar de não tratar, devidamente, os resíduos da Fábrica da Coca-cola antes de lançá-los no rio Jundiaí. Destacou-se que a substância contribui para a desoxigenação da água, mas não foi explicado como isso ocorre. Inclusive, na maioria dos registros, não foi citado qualquer impacto do seu lançamento no ambiente.

De um modo geral, a cobertura jornalística buscou levar a conhecimento público a utilização dessa substância pela atividade da carcinicultura, e seus efeitos prejudiciais à oxigenação dos corpos hídricos. No fim, a culpa recaiu sobre os carcinicultores (a empresa Veríssimo e Filhos, especificamente), mas não pelo uso do metabissulfito de sódio, e sim pelo despejo elevado de matéria orgânica.

\section{Demanda Bioquímica de Oxigênio}

O termo foi utilizado pela primeira vez, na cobertura, quando o vespertino Jornal de Hoje publicou, no dia 10/08/2007, trechos de uma nota elaborada pela Promotoria Estadual de Meio Ambiente, em parceria com professores da UFRN, questionando o laudo técnico preliminar enviado pelo IDEMA. A nota dava a decisão do Instituto como inconclusiva, devido às falhas nas coletas e por desconsiderar a elevada concentração de DBO no efluente da Imunizadora Potiguar, sem especificar valores.

No dia seguinte, os jornais publicaram trechos do laudo técnico preliminar do IDEMA, que atribuíra, à despesca de um viveiro de camarão da empresa Veríssimo e Filhos, a causa do desastre ambiental. O laudo apontava uma estimativa de lançamento em torno de $291,79 \mathrm{~kg}$ a $664,26 \mathrm{~kg}$ de carga de matéria orgânica por hora, resultando numa carga total de 5.544 mil a 12.621 mil kg de matéria orgânica lançada no rio, com base na DBO. No entanto, em momento algum, se buscou esclarecer como esse indicador poderia estimar a quantidade de matéria orgânica despejada no rio.

Em uma notícia acompanhada por um box informativo, no jornal Tribuna do Norte (ASSOCIAÇÃO..., 2007, p. 12), o jornalista buscou definir o termo, porém de forma equivocada, ao escrever a DBO como a "quantidade de oxigênio retirada da água pela matéria orgânica existente em determinado local". Na verdade, o consumo de oxigênio não é praticado 
diretamente pelo composto orgânico, mas é o resultado da atividade respiratória de microorganismos que se alimentam da matéria orgânica. Em suma, a cobertura abordou o termo como uma medida de estimar a carga de matéria orgânica lançada, publicando trechos do laudo técnico do IDEMA na íntegra, sem explicar como é feita essa estimativa, e, em alguns momentos, sem ao menos descrever a sigla DBO.

\section{Eutrofização}

A hipótese do fenômeno Eutrofização estar relacionado com a mortandade dos peixes foi levantada apenas em duas oportunidades, por um jornal, a Tribuna do Norte. No primeiro momento, em notícia publicada no dia 01/08/2007, o então diretor geral do IDEMA, Eugênio Cunha, não descartava essa hipótese. Na segunda notícia, em 12/08/2007, um professor da UFRN não acreditava ser este o motivo do desastre ambiental. Em ambos os casos, os jornalistas buscaram descrever o fenômeno, mesmo de forma superficial. O termo foi relacionado com o enriquecimento do ecossistema aquático por nutrientes diversos, sobretudo "compostos nitrogenados e fosforados", resultando no aumento da quantidade de algas e micro-organismos, num processo que consumiria rapidamente o oxigênio da água. De uma forma resumida, dentro das limitações da produção do jornalismo impresso diário, a cobertura, mesmo que em apenas duas notícias, tratou o termo de forma correta.

\section{Demanda Química de Oxigênio}

Diferentemente dos outros termos analisados pela pesquisa, "Demanda Química de Oxigênio" não se encontra mencionada no período compreendido entre o final de julho e o final de agosto de 2007. Esta expressão foi registrada em uma notícia publicada no dia 04/03/ 2010, no depoimento do então diretor geral do IDEMA, Marco Aurélio Almeida, que havia assumido o cargo em abril de 2009, sucedendo a gestão de Eugênio Cunha no Instituto. A notícia destaca a versão de Marco Aurélio Almeida, que afirma ser impossível atribuir culpa à empresa Veríssimo e Filhos, sob o argumento de que a desoxigenação da água estaria ligada a contaminação química, e não por excesso de matéria orgânica.

Segundo o então diretor do IDEMA,

Uma das variáveis, chamada de DQO (Demanda Química de Oxigênio), que aponta contaminação por químicos, no dia seguinte ao desastre estava em um nível alarmante. Isso seria suficiente para levar a investigação para outro caminho. Eu não saberia apontar quem foi, não tenho essa resposta. Mas sei que a contaminação foi química. (IDEMA..., 2010, p. 9)

O processo administrativo estava tramitando no Conselho Estadual de Meio Ambiente (CONEMA) e, segundo Marco Aurélio Almeida, havia um laudo do IBAMA anexado ao processo que corroborava sua versão. Porém, não há registros de dados sobre este laudo em nenhum dos recortes jornalísticos analisados pela pesquisa. Marco Aurélio ainda destacou que 
o volume da despesca efetuada pela Veríssimo e Filhos era algo bem menor do que o volume indicado pelo laudo do IDEMA de 2007 e corroborado por professores da UFRN, em 2009.

A cobertura jornalística insere, com essa notícia, novos elementos para a discussão quanto à apuração das responsabilidades. No entanto, não oferece os dados sobre os níveis da DQO do dia seguinte ao desastre, e ainda aborda a DQO como apenas um indicador de contaminação por químicos. A grande maioria das referências buscadas pela pesquisa define o termo como um indicador de concentração de matéria orgânica, já que é capaz de medir a quantidade de oxigênio consumido para oxidar a matéria orgânica, biodegradável ou não, por ação de um agente químico oxidante.

\section{Considerações finais}

As coberturas jornalísticas sobre a mortandade de animais apresentam uma característica em comum: iniciam pela busca da causa. Sejam peixes, aves ou mamíferos, o desastre costuma chocar a opinião pública, que passa a cobrar uma justificativa para o ocorrido e, havendo culpados entre os homens, que os mesmos sejam punidos nos rigores da Lei. No caso em estudo, as autoridades competentes buscaram associá-lo, inicialmente, a um fenômeno natural estimulado por condições naturais, até que o laudo técnico preliminar, emitido pelo órgão estadual de meio ambiente, direcionou a apuração da causa para outro caminho.

A partir de então, os acontecimentos construídos pela cobertura da mídia impressa expuseram o confronto de acusações entre os diversos atores envolvidos e suas diferentes versões, cumprindo, assim, com um dos deveres éticos do jornalismo, que é o de buscar uma diversidade de fontes. No entanto, em casos como esses, em que diversas instituições participam das apurações e em que as provas de sustentação de causalidade e de culpabilidade são construídas ao longo do tempo, os jornalistas deveriam recorrer mais às suas ferramentas investigativas, ouvir novas fontes, levantar novas evidências e comparar os laudos emitidos. Ou seja, qualificar a apuração ao longo do tempo, ser mais proativos na busca por explicações causais e recolocar o assunto na pauta jornalística.

Outro aspecto problemático da cobertura analisada foi a ausência de um tratamento mais qualificado dos conceitos científicos que ajudasse a fundamentar melhor os reais motivos relacionados à mortandade de toneladas de fauna aquática em um dos mais importantes estuários do Rio Grande do Norte. Esse aspecto representa um grande desafio neste tipo de situação, por se tratar de um fenômeno ocorrido em uma região estuarina repleta de atividades impactantes com grandes interesses econômicos e políticos, envolvendo questões ligadas à Limnologia e à Oceanografia, pouco conhecidas pela maioria dos jornalistas que participaram da cobertura.

A construção de uma narrativa de causalidade em que eventos naturais, eles próprios complexos, articulam-se com eventos comportamentais e socioeconômicos não é algo trivial, e mereceria um tratamento mais aprofundado, explícito e sistemático. O jornalista que se propõe a investigar desastres ambientais não deveria apenas se alimentar das fontes ligadas ao caso que representa - tal como, normalmente, fazem aqueles que investigam um crime misterioso de assassinato ou de desvio de verba pública - mas necessitaria, também, aprender a 
Dal Pian, L. F.; Alves, D. D. P.

construir inferências fundamentadas em conhecimento científico e tecnológico, e a lidar mais explicitamente com questões epistemológicas e argumentativas. Desta maneira, estaria assumindo um papel mais comprometido com a divulgação científica contemporânea.

Apenas publicar, na integra, trechos de laudos técnicos ou afirmacões de entrevistados com interesses particulares, sem maiores questionamentos sobre a validade de suas versões, de forma acrítica, não contribui, de fato, para aproximar o leitor de uma discussão cidadã. A imprensa deve desempenhar o importante papel de acompanhar as atividades econômicas e as politicas públicas desenvolvidas no entorno do estuário, aprofundando os conceitos, agendando regularmente o debate nas diversas esferas sociais, e utilizando argumentos mais próximos da realidade cotidiana. Caso contrário, estaremos correndo o risco de presenciar novas mortandades, sem realizar qualquer tipo de reflexão que nos faça sentir integrados a uma sociedade mais sustentável.

\section{Referências}

ALBAGLI, S. Divulgação científica: informação científica para a cidadania? Ciência da Informação, Brasília, v. 25, n. 3, p. 396-404, 1996.

ALBUQUERQUE, L. F. Estudo da oxidação do metabissulfito de sódio contido no efluente da carcinicultura. 2005. 85 f. Dissertação (Mestrado em Engenharia Química) Universidade Federal do Rio Grande do Norte, Natal, 2005.

ARAI, M. Sucessão das associações de dinoflagelados (protista, pyrrhophyta) ao longo das colunas estratigráficas do cretáceo das bacias da margem continental brasileira: uma análise sob ponto de vista paleoceanográfico e paleobiogeográfico. 2007. 241 f. Tese (Doutorado em Geociências) - Universidade Federal do Rio Grande do Sul, Porto Alegre, 2007.

ART, H. W. Dicionário de ecologia e ciências ambientais. São Paulo: Melhoramentos, 1998.

ASSOCIAÇÃO acusa Idema de ataque. Tribuna do Norte, Natal, p. 12, 29 ago. 2007.

BARBOSA, M. Narrativa e cerimônia na televisão brasileira: ficcional e factual no acontecimento jornalístico. In: ADAMI, A. et al. (Org.). Mídia, cultura e comunicação 2. São Paulo: Arte \& Ciência, 2003. p. 217-223.

BUENO, W. Comunicação científica e divulgação científica: aproximações e rupturas conceituais. Informação \& Informação, Londrina, v. 15, p. 1-12, 2010. (Número especial).

CÂMARA, I. G. Ciência e tecnologia. In: TRIGUEIRO, A. (Org.). Meio ambiente no século 21: 21 especialistas falam da questão ambiental nas suas áreas de conhecimento. Rio de Janeiro: Sextante, 2003. p. 159-169.

CANDOTTI, E. Divulgação e democratização da ciência. Ciência e Ambiente, Santa Maria, v. 23, p. 5-13, 2001.

CARCINICULTORES vão pedir indenização. Tribuna do Norte, Natal, p. 12, 29 ago. 2007. 
Desafios da divulgação científica ...

CHAVES, E. V. Absorção de metais pesados de solos contaminados do aterro sanitário e pólo industrial de Manaus pelas espécies de plantas Senna multijuga, Schizolobium amazonicum e Caesalpinia echinata. 2008. 87 f. Tese (Doutorado em Biotecnologia) - Universidade Federal do Amazonas, Manaus, 2008.

CRIADOR de camarão acusa imunizadora. Tribuna do Norte, Natal, p. 10, 02 ago. 2007.

DAL PIAN, L. F. Mídia impressa e meio ambiente: um estudo da cobertura da mortandade de peixes no estuário do rio Potengi, Natal/RN. 2011. 114 f. Dissertação (Mestrado em Desenvolvimento e Meio Ambiente) - Universidade Federal do Rio Grande do Norte, Natal, 2011.

DORNELLES, B. O fim da objetividade e da neutralidade no jornalismo cívico e no ambiental. In: GIRARDI, I. M. T.; SCHWAAB, R. T. (Org.). Jornalismo ambiental: desafios e reflexões. Porto Alegre: Dom Quixote, 2008. p. 44-55.

GIRARDI, I. M. T.; SCHWAAB, R. T. (Org.). Jornalismo ambiental: desafios e reflexões. Porto Alegre: Dom Quixote, 2008.

GUEDES, J. Diagnóstico geoquímico-ambiental do rio Jundiaí nas imediações da cidade de Macaíba/RN. 2003. 130 f. Dissertação (Mestrado em Desenvolvimento e Meio Ambiente) - Universidade Federal do Rio Grande do Norte, Natal, 2003.

IDEMA e MP divergem sobre laudo. Tribuna do Norte, Natal, p. 10, 11 ago. 2007.

IDEMA não pode apontar culpados. Tribuna do Norte, Natal, p. 09, 04 mar. 2010.

JARDIM, W. F.; CANELA, M. C. Fundamentos da oxidação química no tratamento de efluentes e remediação de solos. Campinas: Unicamp, 2004. (Caderno temático, 1). Disponível em: <http://lqa.iqm.unicamp.br/cadernos/caderno1.pdf > . Acesso em: 6 out. 2013.

LABOMAR confirma laudo do Idema. Diário de Natal, Natal, p. 08, 28 ago. 2007.

MARCOVITCH, J. Mudanças climáticas e multilateralismo. Revista USP, São Paulo, n. 72, p. 16-27, 2007.

MOTA, J. A. O valor da natureza: economia e política dos recursos naturais. Rio de Janeiro: Garamond, 2001.

PESSOA, F. F. Comparação da cobertura jornalística de acidentes ambientais por veículos impressos de Minas Gerais e Rio de Janeiro. 2008. 88 f. Dissertação (Mestrado em Ciência Florestal) - Universidade Federal de Viçosa, Viçosa, 2008.

ROMANINI, V. Parem as máquinas: relações entre tecnologia, informação e desenvolvimento sustentável. In: BOAS, S. V. (Org.). Formação e informação científica: jornalismo para iniciados e leigos. São Paulo: Summus, 2005. p. 105-123.

SANTANA, G. P. Elemento traço ou metal pesado? [S. 1.: s. n.], 2008. Disponível em: $<$ http://magalhaesmenezes.blogspot.com.br/2011/07/elemento-traco-ou-metalpesado.html>. Acesso em: 15 nov. 2010. 
Dal Pian, L. F.; Alves, D. D. P.

SPERLING, M. V. Introdução à qualidade das águas e ao tratamento de esgotos. 3. ed. Belo Horizonte: Ed. da UFMG, 2005.

TAVARES, T. M.; CARVALHO, F. M. Avaliação de exposição de populações humanas a metais pesados no ambiente: exemplos do recôncavo baiano. Química Nova, São Paulo, v. 15, n. 2, p. 147-154, 1992.

UNIVERSIDADE TECNOLÓGICA FEDERAL DO PARANÁ. Análise de contaminantes ambientais: determinação de amônia. Curitiba, [2002]. Disponível em: <http://pessoal.utfpr.edu.br/colombo/arquivos/N_NH3.pdf>. Acesso em: 10 dez. 2010.

VALENTE, J. P.; PADILHA, P. M.; SILVA, A. M. Oxigênio dissolvido (OD), demanda bioquímica de oxigênio (DBO) e demanda química de oxigênio (DQO) como parâmetros de poluição no ribeirão Lavapés/Botucatu - SP. Eclética Química, São Paulo, v. 22, p. 4966, 1997. Disponível em: <http://dx.doi.org/10.1590/S0100-46701997000100005>. Acesso em: 02 dez. 2011.

Artigo recebido em 03/07/13. Aceito em 26/11/13. 